\title{
A Large-Scale Experimental Study of Gender and Pair Composition in Pair Programming
}

\author{
Lindsay Jarratt \\ lindsay-jarratt@uiowa.edu \\ Educational Policy \& Leadership Studies \\ The University of Iowa \\ Iowa City, Iowa \\ $\mathrm{KC}$ Culver \\ kc-culver@uiowa.edu \\ Educational Policy \& Leadership Studies \\ The University of Iowa \\ Iowa City, Iowa
}

\author{
Nicholas A. Bowman \\ nick-bowman@uiowa.edu \\ Educational Policy \& Leadership Studies \\ The University of Iowa \\ Iowa City, Iowa
}
Alberto Maria Segre
alberto-segre@uiowa.edu
Computer Science
The University of Iowa
Iowa City, Iowa

\begin{abstract}
The proportion of women in computer science majors is currently lower than in any other STEM major. Various studies have sought to explain - and ultimately find ways to reduce - gender disparities in computer science participation and persistence. Pair programming has been proposed as a practice that may not only promote outcomes overall within college and workplace environments, but also help diminish isolation and boost the confidence of women in computer science. Some promising results have been obtained for women in pair programming, but the findings are not consistent across studies, and the limitations of previous research make it difficult to draw strong conclusions. The present study examined 969 undergraduates in several introductory computer science courses who engaged in three different pairings throughout the semester. All pairings were randomly assigned, so the findings reflect the causal influence of the gender pair characteristics on a variety of student outcomes. Overall, having a female partner led to several positive outcomes relative to having a male partner; these included greater lab section attendance as well as greater confidence in the finished product and confidence in the solution for the pair programming assignment. The advantages of having a female partner were occasionally greater for female students than for male students. Overall, the significant findings were most pronounced in the course intended for computer science majors. These results offer evidence for the educational benefits of pair programming for promoting
\end{abstract}

Permission to make digital or hard copies of all or part of this work for personal or classroom use is granted without fee provided that copies are not made or distributed for profit or commercial advantage and that copies bear this notice and the full citation on the first page. Copyrights for components of this work owned by others than the author(s) must be honored. Abstracting with credit is permitted. To copy otherwise, or republish, to post on servers or to redistribute to lists, requires prior specific permission and/or a fee. Request permissions from permissions@acm.org.

ITiCSE '19, July 15-17, 2019, Aberdeen, Scotland UK

(C) 2019 Copyright held by the owner/author(s). Publication rights licensed to ACM.

ACM ISBN 978-1-4503-6301-3/19/07 . .\$15.00

https://doi.org/10.1145/3304221.3319782 women's participation in computer science, as well as the need for careful consideration of pair composition.

\section{CCS CONCEPTS}

- Social and professional topics $\rightarrow$ CS1.

\section{KEYWORDS}

Pair programming; pair characteristics; pair incompatibility; gender; women in computing; computer science; collaborative learning; college students; university students; student outcomes; experimental research; randomized controlled trial.

ACM Reference Format:

Lindsay Jarratt, Nicholas A. Bowman, KC Culver, and Alberto Maria Segre. 2019. A Large-Scale Experimental Study of Gender and Pair Composition in Pair Programming. In Innovation and Technology in Computer Science Education (ITiCSE '19), July 15-17, 2019, Aberdeen, Scotland UK. ACM, New York, NY, USA, 6 pages. https://doi.org/10.1145/3304221.3319782

\section{INTRODUCTION}

The participation of women in computer science is lower than in any other STEM field [10]. The computer science gender gap has also increased notably over time. In fact, $44 \%$ of computer science majors were women in 1980, which then plummeted to $12 \%$ in the mid-2000s and $15 \%$ in 2011 [31]. Despite a broad and intense research program that seeks to address the disparity, this problem has persisted in various Western cultures [36].

Pair programming has been championed as a promising practice that may reduce gender disparities by ending isolation and boosting confidence [3, 26, 37]. and some evidence suggests that the gender composition of pairs may affect outcomes $[11,12,22,32]$. The present large-scale experimental study explores the effects of pair composition on confidence, attendance, understanding of concepts, effort, and productivity. The results demonstrate that gender composition matters, but the results are not entirely consistent with previous literature. Our findings add nuance to an ongoing conversation about the benefits of pair programming, especially how to 
best design and implement pair programming to benefit both male and female students.

The remainder of this paper is organized as follows: Section 2 provides a summary of literature on computer science and pair programming experiences and outcomes through the lens of gender, and Section 3 describes our research methods and analytic procedures. In Section 4, we share our results, followed by a discussion of our findings in Section 5 and possibilities for future research in Section 6.

\section{PREVIOUS RESEARCH}

Many of the explanations for women's underrepresentation in CS focus on possible gendered differences in experience, behavior, and interest. One study found that women and men differed in their "tinkering" behavior and understanding [24], and several studies have pointed to a lack of experience and early exposure to computing (e.g., [4, 10, 24, 33]). Other research has emphasized women's stronger interpersonal orientation [4, 20,31]. Generally, studies have found no gender differences in quantitative or academic ability (e.g., $[5,11,33])$. One national analysis found that academic ability of men and women in CS did sometimes differ, but not in a consistent direction [25]. Despite this similarity in ability, both men and women persistently perceive women's math and computing abilities as being lower than men's $[5,31]$. Relatedly, a consistent finding is that women in CS report lower confidence or self-efficacy in their computing skills - sometimes even less than men who are not CS majors $[4,5,10,25]$. This dynamic may be why women in early CS coursework are less likely to express an identity as a computer scientist [15] and are more likely to be undecided in their career plans [25].

Other explanations focus on the learning environment in CS programs, pointing to a pervasive masculine culture [10]. Beyer [4] found that classroom environment and instruction are powerful predictors for students' decisions to continue in a CS major. There is evidence that pedagogy matters; in a review of findings from published studies from computersupported collaborative learning, researchers observed that gender differences were less pronounced or non-existent in classrooms where participation and inclusion were explicitly promoted [29].

Toward this end, perhaps the most studied pedagogical intervention in CS is pair programming, popularized by proponents of agile programming methods [1]. In the idealized definition of pair programming, two programmers sit sideby-side, sharing one screen and one keyboard to program collaboratively, swapping roles between "driving" or typing code and "navigating" or offering suggestions. A host of studies proclaim the wide benefits of pair programming in terms of coding output, quality of product, reduction in errors, and enjoyment and satisfaction of programmers, to name just a few $[2,14,18,21,27,28,38-40]$. However, the results have not always been consistent $[8,19]$, perhaps because the idealized version of pair programming is often not actualized in practice $[7,13,38]$. Particular attention has been paid to the role of pair compatibility in disparate outcomes of pair programming [9, 22, 23, 34].

While pair programming has shown promising results for all students, the outcomes for women may be more pronounced. Studies show that pair programming boosted confidence of all students with partners (when compared to solo programmers), but that the effects may be larger for women [3, 26, 37]. In interviews, women programmers expressed their appreciation for pair programming, saying that it was useful for time management because they felt responsible to their partners [20].

The gender composition of pairs may also play a moderating role in the success of pair programming as a pedagogical intervention. Several studies have found that same-gender pairs out-perform, are more compatible, and express greater satisfaction than mixed-gender pairs, particularly for women $[11,12,22,32]$. Qualitative responses from women differ after pair-programming experiences based on the gender of their partner: Those in same-gender pairs talk about how the experience increased their comfort, while those in mixedgender pairs talk about difficulties in communication [11]. Similar studies with children working on computer-based problem-solving have observed less cooperation and verbal interaction in mixed-gender pairs [35] and more divergent learning elaboration among mixed-gender pairs, indicating the dominance of one partner [16].

Although the existing scholarship paints pair programming as a promising practice for women, many previous findings did not rise to the level of statistical significance due to small sample sizes. In addition to the lack of statistical power, frequent problems with self-selection have also made it difficult to assess the validity of the results. The current study explores data from a large sample of undergraduate students enrolled in introductory CS coursework to better understand how, if at all, gender composition matters in predicting the outcomes of pair programming.

\section{METHOD}

\subsection{Research Design and Participants}

Participants were undergraduates who took an introductory computer science course at a large, Midwestern research university from Fall 2016 to Spring 2018. The institution has three different introductory courses; the most technical is designed for computer science and statistics majors, the least technical is for humanities majors, and an intermediate course is intended for social and information science majors. Students were included in the sample if they participated in pair programming, were enrolled after the fourth week of the semester (i.e., they had not dropped the class), and were in their first semester in an introductory CS course (some students enrolled in multiple introductory courses or multiple times in the same course). Students engaged in three different pairings during the lab section throughout the course; each pairing lasted for approximately $1 / 3$ of the semester.

Pairings were randomly assigned, but an adjustment was made to increase the likelihood of female-female pairings in 
the most technical class, which had a low representation of female students. Students were assigned to a trio (rather than a pair) if there was an odd number of students in the first lab section of the pairing. Given the presence of multiple partners (and resulting difficulties with measuring partner characteristics), these trios were not included in the analyses. The total analytic sample consisted of 969 undergraduates (41\% female, $24 \%$ computer science majors). The primary unit of analysis was participants' survey responses within a particular pairing. Across all two-person pairings, $40 \%$ were male-male, $34 \%$ were female-male, and $26 \%$ were femalefemale.

\subsection{Measures}

Students frequently participated in multiple surveys and multiple paired assignments during each pairing, but the exact number and timing of these assessments differed as a function of courses, semesters, and pairings. Therefore, in order to create outcome variables with timeframes that corresponded to partner characteristics, students' responses were averaged within each pairing to create the dependent variables. As a result, each student had three different measures of each outcome: one that represented the average across surveys or assignments within the first pairing, one for the second pairing, and one for the third pairing.

The dependent variables included weekly attendance ("Did you attend your discussion section this week?" $0=$ no, $1=$ yes), work accomplished during lab ("What percentage of the assignment were you able to complete during the discussion section?" $1=0-10 \%$, to $10=91-100 \%$ ), and perceptions of productivity ("How productive did you feel during discussion section?" $1=$ not at all productive, to $5=$ very productive). Participants were also asked about their general interest in computer science in each survey ("How interested are you in computer science overall?" $1=$ not at all interested, to 5 $=$ very interested). Additionally, participants indicated their level of agreement ( $1=$ strongly disagree, to $5=$ strongly agree) with the following statements: "I understand all of the concepts used in this assignment"; "I put a good amount of effort into completing this assignment"; "This assignment is error free or has just one or two errors"; "I am confident in the finished product"; and "I enjoyed completing this assignment." Students also rated their own skill relative to their partner $(1=$ my partner has more technical competency, to $3=$ my partner has less technical competency) and their effort ( $1=$ my partner invested more effort in this assignment, to $3=$ my partner invested less effort in this assignment).

The primary independent variables were the gender of the participant and the partner (for both items, $0=$ male, $1=$ female). Technically, this item measured sex, not gender, but we believed that any differences by sex would have occurred as a result of social dynamics pertaining to gender (rather than biological differences by sex). As a result, consistent with previous research, we use "gender" to describe the findings in this study. In addition, an interaction term was created by multiplying the variables for participant gender and partner gender by each other. Dummy variables were also used to indicate for the level of the introductory course (most technical and intermediate, with least technical as the referent group) and the order of the pairing within the semester (second and third, with the initial pairing as the referent group).

\subsection{Analyses}

Students' responses within a pairing, which constituted the primary measurement of the outcome, were nested within two higher-order levels: participants (since each participant engaged in three pairings) and partners (since the partner also worked on the assignment and therefore shaped the outcome). However, neither participants nor partners are hierarchical to each other, since these both occur at the student level. As a result, cross-classified multilevel models were conducted to analyze this complex sample appropriately, with participants and partners crossed with each other (for more information, see $[17,30]$. The key predictors were the participant's gender, partner's gender, and the interaction between the two. Variables for the course level and timing during the semester were also included. Because pairings were randomly assigned, the results for partner's gender can be interpreted as causal effects.

Analyses were conducted within the entire sample and separately for each course. The results were more pronounced for the most technical course than for the other two courses, so subgroup analyses for the most technical course are also presented here. The analyses predicting perceptions of the partner's relative effort in the full sample did not converge successfully, perhaps as the combined result of the complexity of the multilevel model and the relatively modest range of the outcome measure. Therefore, the results for this outcome are only presented for the subgroup analyses.

Supplemental analyses (not reported here) indicate that the results described here are generally consistent when including additional control variables, such as students' interest in computer science. Therefore, it appears that the present findings are largely attributable to gender dynamics rather than other student characteristics. That said, partners' prior experience with computer programming, which varies by gender, does have a notable and unique impact on student outcomes in pair programming [6].

\section{RESULTS}

The results for the full sample are provided in Table 1. Students who were randomly assigned a female partner (rather than a male partner) attended class more often, were more confident that the solution was correct, and more confident in the finished product that they created. However, being assigned a female partner was also associated with completing a smaller percentage of the assignment.

In this same set of analyses, female participants were significantly less likely than male participants to agree that they understood all of the lab concepts, were less confident in the finished assignment, were less interested in computer science, and were more likely to feel that their partner was 
Table 1: Results for cross-classified models predicting student outcomes across all introductory computer science courses. ${ }^{\dagger}$

\begin{tabular}{|c|c|c|c|c|c|c|c|c|c|}
\hline Predictor & $\begin{array}{l}\text { Attended } \\
\text { lab } \\
\text { sections }\end{array}$ & $\begin{array}{l}\text { Understand } \\
\text { concepts } \\
\text { from lab }\end{array}$ & $\begin{array}{l}\text { Confident } \\
\text { solution is } \\
\text { correct }\end{array}$ & $\begin{array}{l}\text { Confident } \\
\text { in finished } \\
\text { product }\end{array}$ & $\begin{array}{l}\text { Percent } \\
\text { assignment } \\
\text { completed }\end{array}$ & $\begin{array}{l}\text { Productive } \\
\text { during lab } \\
\text { section }\end{array}$ & $\begin{array}{l}\text { Exerted } \\
\text { effort on } \\
\text { assignment }\end{array}$ & $\begin{array}{l}\text { Interest in } \\
\text { computer } \\
\text { science }\end{array}$ & $\begin{array}{l}\text { Partner } \\
\text { is less } \\
\text { competent }\end{array}$ \\
\hline \multirow[t]{2}{*}{ Partner is female } & $.045^{*}$ & .018 & $.227^{* *}$ & $.191^{* *}$ & $-.309+$ & .020 & -.013 & .001 & .080 \\
\hline & $(.018)$ & $(.079)$ & $(.070)$ & $(.070)$ & $(.167)$ & $(.063)$ & $(.059)$ & $(.066)$ & $(.053)$ \\
\hline \multirow[t]{2}{*}{ Participant is female } & .033 & $-.276^{* *}$ & -.111 & $-.135+$ & -.273 & -.087 & -.012 & $-.658^{* * *}$ & $-.124^{*}$ \\
\hline & $(.020)$ & $(.090)$ & $(.080)$ & $(.080)$ & $(.223)$ & $(.076)$ & $(.069)$ & $(.094)$ & $(.057)$ \\
\hline \multirow[t]{2}{*}{ Partner $\times$ participant } & -.026 & -.077 & -.131 & -.132 & $.438+$ & .003 & .120 & -.032 & .005 \\
\hline & $(.026)$ & $(.112)$ & $(.100)$ & $(.102)$ & $(.258)$ & $(.094)$ & $(.084)$ & $(.090)$ & $(.072)$ \\
\hline
\end{tabular}

more competent than them. Only one of the relationships exhibited a significant moderation effect: The combination of female participant and female partner led to completing a greater portion of the assignment in class.

Table 2 contains the results for analyses that only examined the most technical course, yielding similar results to the full sample. Relative to students who worked with a male partner, students who worked with a female partner were more confident that their solution was correct, more confident in the finished product, and more likely to attend lab section at all. However, having a female partner instead of a male partner was also associated with completing a smaller proportion of the assignment in class.

In this more technical course, female participants were significantly less likely than male participants to agree that they understood all concepts for the assignment, were less confident in the finished product, were less likely to report that they exerted good effort on completing the assignment, and were less interested in computer science overall. Female participants did attend class more often, but they were also more likely to perceive that their partner was more competent and gave more effort than they did. The interaction of a female participant having a female partner was positively associated with agreeing that they exerted good effort on the assignment as well as feeling that their partner was less competent and exerted less effort than they did.

\section{DISCUSSION}

This randomized controlled trial provides strong evidence that pair composition affects some student outcomes. In particular, students are more confident about their work - and even more likely to attend the lab section in the first placewhen they are randomly assigned a female partner rather than a male partner. These patterns are consistent among all introductory computer science courses and specifically within the course designed for majors, which serves a particularly important function for shaping the demographics of computer science professionals. For the most part, the positive effects for female partners are apparent regardless of the participant's own gender. Thus, the present findings support an additional argument for promoting the representation of female students within computer science: Working with female students in pair programming may bolster the academic outcomes of all students. These results in a higher education context run contrary to previous studies of children that suggest male students benefit from interacting with a male partner [16, 35].

As shown in the interaction analyses, female students sometimes benefit even more than male students as a result of being assigned a female partner. The particular results differ across analyses; when examining all courses, having a female partner yielded a significantly greater gain in the percentage of the assignment completed among female students than among male students. Within the course designed for majors, working with a female partner had more favorable effects for female students in terms of exerting more effort on the assignment and perceiving themselves as having greater competence and effort than their partner. Taken as a whole, it appears that facilitating female-female pairings may be an especially effective approach.

However, the interpretation for the competence and effort findings may be complicated. These items specifically asked participants whether their competency and effort were lower than, similar to, or higher than that their partner's attributes. As one interpretation of the positive relationships for these variables, this same-gender pairing may lead to improvements in self-perceptions, which then lead to greater ratings in comparison with the partner. The positive finding for the female $\times$ female interaction and exerting effort appears to support this explanation for effort, whereas the lack of significant results for other outcomes (such as confidence in the solution and the finished product) does not. It is worth noting that prior research has also yielded some favorable results for female-female pairings [11, 12, 22, 32].

Finally, the differences between female and male students were consistent with previous research (e.g., [4, 5, 25]). Among all courses and within the most technical course, female students were less likely to feel that they understood concepts from lab, were less confident in their finished product, had lower perceptions of their competence relative to their partner, and had less interest in computer science overall. Unfortunately, although pair programming may help to reduce gender disparities, this pedagogical approach does not completely remedy this issue. 
Table 2: Results for cross-classified models predicting student outcomes in the most technical introductory computer science course. ${ }^{\ddagger}$

\begin{tabular}{|c|c|c|c|c|c|c|c|c|c|c|}
\hline Predictor & $\begin{array}{l}\text { Attended } \\
\text { lab } \\
\text { sections }\end{array}$ & $\begin{array}{l}\text { Understand } \\
\text { concepts } \\
\text { from lab }\end{array}$ & $\begin{array}{l}\text { Confident } \\
\text { solution is } \\
\text { correct }\end{array}$ & $\begin{array}{l}\text { Confident } \\
\text { in finished } \\
\text { product }\end{array}$ & $\begin{array}{l}\text { Percent } \\
\text { assignment } \\
\text { completed }\end{array}$ & $\begin{array}{l}\text { Productive } \\
\text { during lab } \\
\text { section }\end{array}$ & $\begin{array}{l}\text { Exerted } \\
\text { effort on } \\
\text { assignment }\end{array}$ & $\begin{array}{l}\text { Interest in } \\
\text { computer } \\
\text { science }\end{array}$ & $\begin{array}{l}\text { Partner } \\
\text { is less } \\
\text { competent }\end{array}$ & $\begin{array}{l}\text { Partner } \\
\text { gave less } \\
\text { effort }\end{array}$ \\
\hline Partner is female & $\begin{array}{l}.043^{*} \\
(.022)\end{array}$ & $\begin{array}{l}.104 \\
(.119)\end{array}$ & $\begin{array}{l}.243^{*} \\
(.112)\end{array}$ & $\begin{array}{l}.253^{*} \\
(.111)\end{array}$ & $\begin{array}{l}-.384+ \\
(.200)\end{array}$ & $\begin{array}{l}.094 \\
(.090)\end{array}$ & $\begin{array}{l}.077 \\
(.093)\end{array}$ & $\begin{array}{l}.130 \\
(.094)\end{array}$ & $\begin{array}{l}.069 \\
(.084)\end{array}$ & $\begin{array}{l}-.069 \\
(.069)\end{array}$ \\
\hline Participant is female & $\begin{array}{l}.046+ \\
(.025)\end{array}$ & $\begin{array}{l}-.454^{* *} \\
(.140)\end{array}$ & $\begin{array}{l}-.207 \\
(.138)\end{array}$ & $\begin{array}{l}-.235+ \\
(.135)\end{array}$ & $\begin{array}{l}.021 \\
(.412)\end{array}$ & $\begin{array}{l}-.113 \\
(.122)\end{array}$ & $\begin{array}{l}-.228^{*} \\
(.115)\end{array}$ & $\begin{array}{l}-.486^{* *} \\
(.153)\end{array}$ & $\begin{array}{l}-.243^{*} \\
(.095)\end{array}$ & $\begin{array}{l}-.171^{*} \\
(.073)\end{array}$ \\
\hline Partner $\times$ participant & $\begin{array}{l}-.024 \\
(.039)\end{array}$ & $\begin{array}{l}.081 \\
(.214)\end{array}$ & $\begin{array}{l}-.246 \\
(.214)\end{array}$ & $\begin{array}{l}-.171 \\
(.213)\end{array}$ & $\begin{array}{l}.401 \\
(.401)\end{array}$ & $\begin{array}{l}-.037 \\
(.169)\end{array}$ & $\begin{array}{l}.312+ \\
(.171)\end{array}$ & $\begin{array}{l}-.006 \\
(.171)\end{array}$ & $\begin{array}{l}.406^{* *} \\
(.147)\end{array}$ & $\begin{array}{l}.288^{*} \\
(.120)\end{array}$ \\
\hline
\end{tabular}

\section{CONCLUSION AND FUTURE WORK}

Our study corroborates claims that the gender composition of pairs moderates the effects of pair programming. However, unlike previous results on the apparent benefits of samegender pairs, our findings suggest that having a female partner seems to benefit both male and female students, adding further urgency to the need to recruit more women into CS. Given the increased benefits for female students and their stark underrepresentation, instructors utilizing pair programming should consider overrepresenting female-female pairings relative to random chance.

It is not entirely clear why such a discrepancy exists between our findings and the previous literature. It may be a result of the differences in context or from using random assignment for establishing pair groups instead of allowing students to select their own partners. Additionally, the more pronounced effects in the most technically difficult course may suggest that experience and/or commitment to computer science moderates the role of gender compatibility in pair programming, but more work is necessary to understand these relationships. Finally, these findings may simply be idiosyncratic to our particular implementation of pair programming (although we are unsure about what those idiosyncratic attributes might be).

Future research should examine the effects of gender composition when pairs are assigned by instructors versus chosen by students. The present results may not hold if, for instance, female-female pairings were a result of male students only choosing each other. In this vein, scholarship should begin turning to the ideal conditions under which pair programming should be implemented and where it is most successful. How do classroom climate and environmental cues affect the dynamics of gender in paired relationships? Which instructor practices encourage equitable and productive relationships? Finally, more work is needed that explores the effects of pair composition on longer-term outcomes, such as taking subsequent computer science courses and persisting with computer science majors.

\section{ACKNOWLEDGMENTS}

This material is based upon work supported by the National Science Foundation under Grant No. 1611908 (AMS and NAB, CoPIs). Any opinions, findings, and conclusions or recommendations expressed in this material are those of the authors and do not necessarily reflect the views of the National Science Foundation. The authors wish to thank Professors James Cremer, Ines Curto, and Denise Szecsei as well as graduate teaching assistants Abhijeet Kharkar and Sai Kalyan Moguloju from the University of Iowa Computer Science Department for their support and assistance during the data collection portion of this study.

\section{REFERENCES}

[1] K. Beck, M. Beedle, A. van Bennekum, A. Cockburn, W. Cunningham, M. Fowler, J. Grenning, J Highsmith, A. Hunt, R. Jeffries, J. Kern, B. Marick, R.C. Martin, S. Mellor, K. Schwaber, J. Sutherland, and D. Thomas. 2001. Manifesto for agile software development. http://www.agilemanifesto.org

[2] A. Begel and N. Nagappan. 2008. Pair programming: What's in it for me?. In Proceedings of the second ACM-IEEE international symposium on empirical software engineering and measurement ESEM08. ACM Press, Kaiserslautern, Germany, 120-128. https: //doi.org/10.1145/1414004.1414026

[3] S.B. Berenson, K.M. Slaten, L. Williams, and C-W. Ho. 2004. Voices of women in a software engineering course: Reflections on collaboration. Journal on Educational Resources in Computing (JERIC) 4, 1 (2004), 3. https://doi.org/10.1145/1060071. 1060074

[4] S. Beyer. 2014. Why are women underrepresented in computer science? Gender differences in stereotypes, self-efficacy, values, and interests and predictors of future CS course-taking and grades. Computer Science Education 24, 2-3 (July 2014), 153-192. https: //doi.org/10.1080/08993408.2014.963363

[5] S. Beyer, K. Rynes, J. Perrault, K. Hay, and S. Haller. 2003. Gender differences in computer science students. ACM SIGCSE Bulletin 35, 1 (2003), 49-53.

[6] N.A. Bowman, L. Jarratt, K.C. Culver, and A.M. Segre. 2019. How Prior Programming Experience Affects Students' Pair Programming Experiences and Outcomes. In ACM Conference on Innovation and Technology in Computer Science Education (ITiCSE19). ACM, New York, NY.

[7] S. Bryant, P. Romero, and B. du Boulay. 2008. Pair programming and the mysterious role of the navigator. International journal of human-computer studies 66, 7 (July 2008), 519-529. https: //doi.org/10.1016/j.ijhcs.2007.03.005

[8] G. Canfora, A. Cimitile, G.A. Di Lucca, and C.A. Visaggio. 2006. How distribution affects the success of pair programming. International Journal of Software Engineering and Knowledge Engineering 16, 02 (April 2006), 293-313. https: //doi.org/10.1142/S0218194006002756

[9] E.A. Chaparro, A. Yuksel, P. Romero, and S. Bryant. 2005. Factors affecting the perceived effectiveness of pair programming in higher education. In Proceedings of the Psychology of Programming Interest Group (Brighton, UH). 5-18.

[10] S. Cheryan, S.A. Ziegler, A.K. Montoya, and L. Jiang. 2017. Why are some STEM fields more gender balanced than others? Psychological Bulletin 143, 1 (Jan. 2017), 1-35. https://doi.org/ $10.1037 /$ bul0000052 
[11] K.S. Choi. 2015. A comparative analysis of different gender pair combinations in pair programming. Behaviour $\&$ Information Technology 34, 8 (Aug. 2015), 825-837. https://doi.org/10.1080/ 0144929X.2014.937460

[12] K.S. Choi, F.P. Deek, and I. Im. 2009. Pair dynamics in team collaboration. Computers in Human Behavior 25, 4 (July 2009), 844-852. https://doi.org/10.1016/j.chb.2008.09.005

[13] J. Chong and T. Hurlbutt. 2007. The social dynamics of pair programming. In 29th International Conference on Software Engineering (ICSE'O7). IEEE, Minneapolis, MN, 354-363. https: //doi.org/10.1109/ICSE.2007.87

[14] T.H. DeClue. 2003. Pair programming and pair trading: Effects on learning and motivation in a CS2 course. Journal of computing sciences in colleges 18, 5 (May 2003), 49-56. http://dl.acm.org/ citation.cfm?id $=771832.771843$

[15] J. Dempsey, R.T. Snodgrass, I. Kishi, and A. Titcomb. 2015. The emerging role of self-perception in student intentions. In Proceedings of the 46th ACM technical symposium on computer science education - SIGCSE15. ACM Press, Kansas City, MO, 108-113. https://doi.org/10.1145/2676723.2677305

[16] N. Ding, R.J. Bosker, and E.G. Harskamp. 2011. Exploring gender and gender pairing in the knowledge elaboration processes of students using computer-supported collaborative learning. Computers \&6 Education 56, 2 (Feb. 2011), 325-336. https://doi.org/10.1016/j.compedu.2010.06.004

[17] A. Fielding and H. Goldstein. 2006. Cross-classified and multiple membership structures in multilevel models: An introduction and review. Technical Report Research Report no. 791. University of Birmingham, Birmingham, UK.

[18] B. Hanks, C. McDowell, D. Draper, and M. Krnjajic. 2004. Program quality with pair programming in CS. In Proceedings of the 9th annual SIGCSE conference on innovation and technology computer science education. Leeds, UK, 176-180.

[19] S. Heiberg, U. Puus, P. Salumaa, and A. Seeba. 2003. Pair programming effect on developers productivity. In Extreme programming and agile processes in software engineering., M Marchesi and G Succi (Eds.). XP 2003. Lecture notes in computer science, Vol. 2675. Springer, Berlin, Heidelberg, 215-224.

[20] C-W. Ho, K. Slaten, L. Williams, and S. Berenson. 2004. Examining the impact of pair programming on female students. Technical Report NCSU CSC Technical Report 2004-20. North Carolina State University.

[21] E.V. Howard. 2006. Attitudes on using pair-programming. Journal of Educational Technology Systems 35, 1 (Sept. 2006), 89-103. https://doi.org/10.2190/5K87-58W8-G07M-2811

[22] N. Katira, L. Williams, and J. Osborne. 2005. Towards increasing the compatibility of student pair programmers. In Proceedings of the 27th international conference on software engineering. IEEE, St. Louis, MO, 625-626.

[23] N. Katira, L. Williams, E. Wiebe, C. Miller, S. Balik, and E Gehringer. 2004. On understanding compatibility of student pair programmers. In Proceedings of the 35th SIGCSE technical symposium on computer science education. Norfolk, VA, 7-11.

[24] S. Krieger, M. Allen, and C. Rawn. 2015. Are females disinclined to tinker in computer science?. In Proceedings of the 46th ACM Technical Symposium on Computer Science Education - SIGCSE '15. ACM Press, Kansas City, MO, 102-107. https://doi.org/10. $1145 / 2676723.2677296$

[25] K.J. Lehman, L.J. Sax, and H.B. Zimmerman. 2016. Women planning to major in computer science: Who are they and what makes them unique? Computer Science Education 26, 4 (Dec 2016), 277-298. https://doi.org/10.1080/08993408.2016.1271536
[26] C. McDowell, L. Werner, H.E. Bullock, and J. Fernald. 2006. Pair programming improves student retention, confidence, and program quality. Commun. ACM 49, 8 (Aug. 2006), 90-95. https://doi.org/10.1145/1145287.1145293

[27] E. Mendes, L. Al-Fakhri, and A. Luxton-Reilly. 2006. A replicated experiment of pair-programming in a 2nd-year software development and design computer science course. ACM SIGCSE Bulletin 38, 3 (2006), 108-112.

[28] N. Nagappan, L. Williams, M. Ferzli, E. Wiebe, K. Yang, C. Miller, and S. Balik. 2003. Improving the CS1 experience with pair programming. ACM SIGCSE Bulletin 35, 1 (2003), 359-362.

[29] F.R. Prinsen, M.L.L. Volman, and J. Terwel. 2007. Gender-related differences in computer-mediated communication and computersupported collaborative learning: Gender-related differences in CMC and CSCL. Journal of Computer Assisted Learning 23, 5 (Feb. 2007), 393-409. https://doi.org/10.1111/j.1365-2729.2007. 00224.x

[30] S.W. Raudenbush and A.S. Bryk. 2002. Hierarchical linear models: Applications and data analysis methods (2nd ed.). Sage Publications, Thousand Oaks, CA.

[31] L.J. Sax, K.J. Lehman, J.A. Jacobs, M.A. Kanny, G. Lim, L. Monje-Paulson, and H.B. Zimmerman. 2017. Anatomy of an enduring gender gap: The evolution of women's participation in computer science. The Journal of Higher Education 88, 2 (March 2017), 258-293. https://doi.org/10.1080/00221546.2016.1257306

[32] S. Schiller, F. Nah, B. Mennecke, and K. Siau. 2011. Gender differences in virtual collaboration on a creative design task. In ICIS 2011 Proceedings.

[33] J. Sinclair and S. Kalvala. 2015. Exploring societal factors affecting the experience and engagement of first year female computer science undergraduates. In Proceedings of the 15th Koli Calling Conference on Computing Education Research Koli Calling '15. ACM Press, Koli, Finland, 107-116. https: //doi.org/10.1145/2828959.2828979

[34] L. Thomas, M. Ratcliffe, and A. Robertson. 2003. Code warriors and code-a-phobes: A study in attitude and pair programming. ACM SIGCSE Bulletin 35, 1 (2003), 363-367.

[35] J. Underwood, G. Underwood, and D. Wood. 2000. When does gender matter? Interactions during computer-based problem solving. Learning and Instruction 10, 5 (2000), 447-462.

[36] A. Vitores and A. Gil-Juarez. 2016. The trouble with 'women in computing': A critical examination of the deployment of research on the gender gap in computer science. Journal of Gender Studies 25, 6 (Nov. 2016), 666-680. https://doi.org/10.1080/09589236. 2015.1087309

[37] L.L. Werner, B. Hanks, and C. McDowell. 2004. Pair-programming helps female computer science students. Journal on Educational Resources in Computing 4, 1 (March 2004), 1-8. https://doi. org $/ 10.1145 / 1060071.1060075$

[38] E.N. Wiebe, L. Williams, J. Petlick, N. Nagappan, S. Balik, C. Miller, and M. Ferzli. 2003. Pair programming in introductory programming labs. In Proceedings Submitted to the American Society for Engineering Education Annual Conference and Exposition (Washington, DC).

[39] L. Williams and R. Kessler. 2002. Pair programming illuminated. Addison-Wesley, Boston, MA.

[40] L. Williams, C. McDowell, N. Nagappan, J. Fernald, and L. Werner. 2003. Building pair programming knowledge through a family of experiments. In 2003 International Symposium on Empirical Software Engineering, 2003. ISESE 2003. Proceedings. IEEE Comput. Soc, Rome, Italy, 143-152. https: //doi.org/10.1109/ISESE.2003.1237973 